\title{
Compliance with Atypical Antipsychotic Triage Guidelines by Texas Poison Centers
}

\author{
Mathias B. Forrester
}

Published online: 17 April 2010

(C) American College of Medical Toxicology 2010

\begin{abstract}
Triage guidelines for poison center management of atypical antipsychotic ingestions were published in December 2007. This investigation determined whether Texas poison centers already complied with a simplified version of these guidelines. All acute aripiprazole, clozapine, olanzapine, quetiapine, risperidone, and ziprasidone ingestions reported to Texas poison centers during 20002007 were identified. Exclusion criteria were the presence of coingestants, patient already at or en route to a healthcare facility when the poison center was contacted, and chronic ingestion. Each case was evaluated whether it was managed in compliance with the simplified triage guidelines and the compliance rate calculated. For 2,611 total cases, the compliance rate was $64.1 \%$. The rate was $71.7 \%$ for aripiprazole, $43.6 \%$ for clozapine, $71.6 \%$ for olanzapine, $60.8 \%$ for quetiapine, $65.5 \%$ for risperidone, and $59.0 \%$ for ziprasidone. The majority of acute atypical antipsychotic ingestions reported to Texas poison centers were managed according to a simplified version of recommended triage algorithm.
\end{abstract}

Keywords Atypical antipsychotic .

Management guidelines · Poison center

Funding for this research was provided by a contract with the Commission on State Emergency Communications in Texas.

M. B. Forrester ( $\square)$

Epidemiology and Disease Surveillance Unit,

Department of State Health Services,

$1100 \mathrm{~W} 49$ th Street,

Austin, TX 78756, USA

e-mail: mathias.forrester@dshs.state.tx.us

\section{Introduction}

Atypical antipsychotics (second generation antipsychotics) are a prescribed class of drugs approved by the US Food and Drug Administration for the management of psychiatric conditions. Among the atypical antipsychotics available in the USA are aripiprazole, clozapine, olanzapine, quetiapine, risperidone, and ziprasidone.

The number of atypical antipsychotic exposures reported to US poison centers has increased each year since 2001 [1-7]. In 2007, 41,607 atypical antipsychotic exposures were reported to US poison centers, accounting for $1.7 \%$ of all exposures that year [7].

A group associated with the American Association of Poison Control Centers (AAPCC) published detailed management guidelines for atypical antipsychotic ingestions in December 2007 [8]. However, the utility of these guidelines has not been evaluated. The objective of this investigation was to evaluate the degree to which poison centers already complied with a simplified version of these guidelines prior to their publication. The author had performed a similar evaluation of the AAPCC management guidelines for selective serotonin reuptake inhibitors $[9,10]$.

\section{Materials and Methods}

This was a retrospective study using data from the Texas Poison Center Network (TPCN), which consists of six poison centers that together service Texas, a population of over 20 million. All of the Texas poison centers use a single database to collect information on all calls in a similar manner. Prior to December 2007, the TPCN did not have standardized management guidelines for atypical antipsychotic ingestions. 
Cases were all acute ingestions of aripiprazole, clozapine, olanzapine, quetiapine, risperidone, and ziprasidone reported to the TPCN during 2000-2007. Ingestions involving other substances and chronic and acuteon-chronic ingestions were excluded. Ingestions where the patient was already at or en route to a health-care facility when the poison center was contacted were also excluded.

The following variables were identified for each case: specific atypical antipsychotic, dose ingested, patient age, circumstances of (reason for) the ingestion, severity of the medical outcome, management site, year, and poison center to which the ingestion was initially reported. The groupings for most of the variables were based on the code groupings used in the database as defined by the AAPCC.

The reported dose ingested is usually not recorded in the TPCN database in a readily available manner. Therefore, the author reviewed the dose, quantity, concentration, verbatim substance name, and notes fields in order to determine the dose. For a portion of the ingestions, the number of tablets or capsules was reported, but the formulation was not. For these cases, a maximum possible dose was calculated using the maximum daily formulation available for that particular atypical antipsychotic. For those ingestions where the quantity ingested was reported to be a "taste," the quantity was considered to be $1 / 10$ of a tablet or capsule.

The circumstances of the ingestion were divided into those involving self-harm or malicious intent (intentional suspected attempted suicide, contamination/tampering, malicious) and all other circumstances (all unintentional ingestions, adverse drug reactions, intentional misuse and abuse, unknown).

The final medical outcome is assigned by the poison center staff managing the case based on the observed or likely adverse clinical effects. The final medical outcome subgroups in the TPCN database are defined as follows:

No effect (no symptoms due to exposure)

Minor effect (some minimally troublesome symptoms) Moderate effect (more pronounced, prolonged symptoms)

Major effect (symptoms that are life threatening or cause significant disability)

Death

Not followed, judged as nontoxic exposure (clinical effects not expected)

Not followed, minimal clinical effects possible (no more than minor effect possible, e.g., therapeutic effects)

Unable to follow, judged as a potentially toxic exposure Unrelated effect, the exposure was probably not responsible for the effect(s)

Confirmed nonexposure
The suggested AAPCC management guidelines' triage algorithm requires detailed information on an ingestion when deciding whether to refer a patient to a health-care facility. This includes knowledge of the circumstances of the ingestion, whether the home situation is of concern, the symptoms present when the poison center was first contacted, time since the ingestion, whether the ingestion was acute or chronic, patient age, and dose ingested [8]. All of this information was not necessarily recorded in the TPCN database. Thus, the author created a simplified version of the triage algorithm that included only the circumstances of the ingestion, the patient age, and reported amount ingested (Table 1). The compliance rate (proportion of total cases that were managed according to this simplified triage algorithm) was determined for total cases and for selected variables.

The Texas Department of State Health Services institutional review board considers this investigation exempt from ethical review.

\section{Results}

Of 2,611 total cases, 1,674 (64.1\%) were managed according to the simplified triage guidelines. When compliance was examined by the various steps in the triage guidelines (Table 1), almost all of ingestions involving suspected attempted suicide or malicious attempt were managed according to the guidelines (referred to a healthcare facility). Of the remaining ingestions, most of those where the dose could not be determined or estimated were also managed according to the guidelines (referred to a health-care facility). For the remaining cases where the reported or estimated dose was greater than the threshold dose, the majority were not managed according to the guidelines (referred to a health-care facility) while most of those cases with a reported or estimated dose less than or equal to the threshold dose were managed according to the guidelines (managed on site). Of the 1,449 ingestions that should have been referred to a health-care facility (first three rows of Table 1), 537 (37.1\%) were managed on site. Of the 1,162 ingestions that should have been managed on site (fourth row of Table 1), 400 (34.4\%) were referred to a health-care facility. The majority of those ingestions that were not managed according to the simplified guidelines were not referred to a health-care facility when the guidelines directed that they should.

Table 2 presents the compliance rate with respect to various demographic and clinical factors. The compliance rate varied between the specific medications, being highest for aripiprazole and lowest for clozapine. The compliance rate was slightly lower for patients aged less than 12 years than for patients aged 12 years or greater. While the majority 
Table 1 Simplified triage management guidelines for acute ingestions of atypical antipsychotics alone and whether Texas Poison Center Network cases during 2000-2007 would have followed the guidelines

\begin{tabular}{|c|c|c|c|c|}
\hline \multirow[t]{2}{*}{ Algorithm for triage of atypical antipsychotic ingestions } & \multicolumn{4}{|c|}{ Guidelines followed? } \\
\hline & Yes & No & Total & $\%$ Yes \\
\hline Is self-harm, suicidal, or malicious intent suspected? (Yes=to HCF; no=continue below) & 517 & 5 & 522 & 99.0 \\
\hline Unable to estimate maximum amount ingested? $(\mathrm{Yes}=$ to $\mathrm{HCF}$; no=continue below) & 124 & 49 & 173 & 71.7 \\
\hline Maximum total amount possible $>$ threshold dose? $($ Yes $=$ to $\mathrm{HCF}$; no=continue below) & 271 & 483 & 754 & 35.9 \\
\hline Maximum total amount possible $\leq$ threshold dose $?(Y e s=$ on site $)$ & 762 & 400 & 1,162 & 65.6 \\
\hline Total & 1,674 & 937 & 2,611 & 64.1 \\
\hline
\end{tabular}

Excludes ingestions where the patient was already at or en route to a HCF when the poison center was contacted or the management site was unknown

$H C F$ health-care facility

of the ingestions of doses equal to the threshold dose or less were managed according to the simplified triage guidelines, most of those ingestions of doses greater than the threshold dose but less than or equal to twice the threshold dose were not managed according to the guidelines. Most of the ingestions of doses greater than twice the threshold dose were managed according to the guidelines. The compliance rate increased with the severity of the medical outcome and was greater for ingestions with a known final medical outcome than for ingestions that were not followed to a final medical outcome. There was no annual trend in compliance rate. The compliance rate in 2000-2003 was $63.7 \%$ and in 2004-2007 was $64.3 \%$. The compliance rate varied between the six poison centers from $61.3 \%$ to $68.9 \%$.

\section{Discussion}

The number of atypical antipsychotic exposures has increased over a recent 7-year period, and in 2007, atypical antipsychotics accounted for almost $2 \%$ of exposures reported to US poison centers [1-7]. However, all poison centers do not have management guidelines for atypical antipsychotic ingestions. In December 2007, a group associated with the AAPCC drafted detailed management guidelines for atypical antipsychotic ingestions [8]. This investigation attempted to evaluate the utility of these guidelines by identifying what proportion of acute atypical antipsychotic ingestions reported to Texas poison centers during 2000-2007 were managed according to a simplified triage algorithm based on the recommended guidelines.

This study was subject to various limitations. The investigation used data already collected by the TPCN and recorded in its database. This database did not contain information that would allow evaluation of the actual recommended triage algorithm, so a simplified version of the triage algorithm had to be used. It is possible that some of the ingestions that were not managed according to the simplified triage guidelines had been managed according to the recommended triage guidelines.

In addition, the dose ingested was not recorded consistently in the database. Furthermore, it should be noted that the dose ingested was often reported by non-health-care providers describing the number of tablets or capsules ingested and the product formulation, information that may not be accurate. Furthermore, in a portion of cases, the number of tablets or capsules that were ingested was reported, but the formulation was not. For the purpose of this investigation, an estimation of the maximum possible ingested dose was made using the maximum daily formulation for the medication. The maximum possible dose may represent an over-estimate for a portion of these cases. However, when poison center staffs are faced with such a situation when deciding how to manage such an ingestion, the staffs generally use the maximum formulation. To do otherwise might result in a patient who needs to be referred to a health-care facility being managed on site, a situation that might be hazardous to the patient. Using the maximum formulation might result in referral of a patient to a health-care facility when the patient does not need to, a situation less likely to be hazardous to the patient but would result in unnecessary medical expenses.

This investigation found that most of the acute atypical antipsychotic ingestions were managed according to the simplified triage algorithm. This suggests that the triage algorithm of the recommended AAPCC atypical antipsychotic management guidelines, or some variation thereof, is useful. However, of those ingestions that were not managed according to the simplified guidelines, most were not referred to a health-care facility when the guidelines directed that they should.

The degree of compliance varied with the type of ingestion. Ingestions involving suspected attempted suicide 
Table 2 Compliance with simplified triage management algorithm for ingestions of atypical antipsychotics alone reported to the Texas Poison Center Network during $2000-2007$ by selected factors
Excludes ingestions where the patient was already at or en route to a HCF when the poison center was contacted or the management site was unknown

$H C F$ health-care facility

${ }^{a}$ All of the cases did not fit into the categories

\begin{tabular}{|c|c|c|c|c|}
\hline \multirow[t]{2}{*}{ Factor } & \multicolumn{4}{|c|}{ Guidelines followed? } \\
\hline & Yes & No & Total & $\%$ yes \\
\hline Total & 1,674 & 937 & 2,611 & 64.1 \\
\hline \multicolumn{5}{|l|}{ Atypical antipsychotic drug } \\
\hline Aripiprazole & 130 & 51 & 181 & 71.8 \\
\hline Clozapine & 17 & 22 & 39 & 43.6 \\
\hline Olanzapine & 292 & 116 & 408 & 71.6 \\
\hline Quetiapine & 635 & 410 & 1,045 & 60.8 \\
\hline Risperidone & 472 & 249 & 721 & 65.5 \\
\hline Ziprasidone & 128 & 89 & 217 & 59.0 \\
\hline \multicolumn{5}{|l|}{ Patient age (years) ${ }^{\mathrm{a}}$} \\
\hline$<12$ & 606 & 387 & 993 & 61.0 \\
\hline$\geq 12$ & 1,038 & 541 & 1,579 & 65.7 \\
\hline \multicolumn{5}{|l|}{ Threshold dose $\mathrm{e}^{\mathrm{a}}$} \\
\hline$\leq$ Threshold dose & 692 & 135 & 827 & 83.7 \\
\hline$>$ Threshold dose and $\leq 2 \times$ threshold dose & 104 & 267 & 371 & 28.0 \\
\hline$>2 \times$ threshold dose & 629 & 477 & 1,106 & 56.9 \\
\hline \multicolumn{5}{|l|}{ Medical outcome } \\
\hline No effect & 358 & 217 & 575 & 62.3 \\
\hline Minor effect & 212 & 93 & 305 & 69.5 \\
\hline Moderate effect & 106 & 27 & 133 & 79.7 \\
\hline Major effect & 20 & 0 & 20 & 100.0 \\
\hline Not followed: judged nontoxic & 41 & 59 & 100 & 41.0 \\
\hline Not followed: judged minimally toxic & 419 & 463 & 882 & 47.5 \\
\hline Unable to follow: judged potentially toxic & 500 & 57 & 557 & 89.8 \\
\hline Unrelated effect & 8 & 8 & 16 & 50.0 \\
\hline Subsequent confirmed nonexposure & 10 & 13 & 23 & 43.5 \\
\hline \multicolumn{5}{|l|}{ Year } \\
\hline 2000 & 58 & 39 & 97 & 59.8 \\
\hline 2001 & 108 & 43 & 151 & 71.5 \\
\hline 2002 & 145 & 94 & 239 & 60.7 \\
\hline 2003 & 204 & 118 & 322 & 63.4 \\
\hline 2004 & 305 & 156 & 461 & 66.2 \\
\hline 2005 & 302 & 158 & 460 & 65.7 \\
\hline 2006 & 282 & 160 & 442 & 63.8 \\
\hline 2007 & 270 & 169 & 439 & 61.5 \\
\hline \multicolumn{5}{|l|}{ Poison center } \\
\hline $\mathrm{A}$ & 98 & 62 & 160 & 61.3 \\
\hline B & 363 & 164 & 527 & 68.9 \\
\hline $\mathrm{C}$ & 150 & 72 & 222 & 67.6 \\
\hline $\mathrm{D}$ & 432 & 273 & 705 & 61.3 \\
\hline $\mathrm{E}$ & 293 & 157 & 450 & 65.1 \\
\hline $\mathrm{F}$ & 338 & 209 & 547 & 61.8 \\
\hline
\end{tabular}

or malicious intent, ingestions where the dose ingested was not reported or could not be estimated, and ingestion of the threshold dose or less resulted in compliance in the majority of cases. However, ingestion of more than the threshold dose did not; that is, the majority of such ingestions were managed on site when the guidelines indicated they should have been referred to a health-care facility. Only $28 \%$ of ingestions of doses greater than the threshold dose but less than or equal to twice the threshold dose were managed according to the guidelines. For even higher doses, the compliance rate more than doubled, but $43 \%$ were not managed according to the guidelines. This suggests that the 
threshold doses might need to be reevaluated. Although ingestions of doses greater than the threshold dose but less than or equal to twice the threshold dose accounted for only $16 \%$ of total ingestions of a known or estimated dose, almost half had a known or estimated higher dose.

The compliance rate increased with the severity of the medical outcome. This indicates that those ingestions more likely to have adverse outcomes appear to have been managed appropriately.

The compliance rate also varied widely by the specific atypical antipsychotic. The reason for this variation is unclear. One potential explanation is that poison center staff experience managing ingestions might have varied by the type of atypical antipsychotic. If they did not have much experience with a particular drug, they might have been more likely to have referred ingestions of that drug to health-care facilities. While the compliance rate was $59 \%$ or greater for five of the six medications, the majority of clozapine ingestions were not managed according to the simplified triage guidelines. However, it should be noted that there were few acute clozapine ingestions included in the study.

The compliance rate might be expected to increase over time as poison center staff become more experienced managing atypical antipsychotic ingestions. However, no such annual trend was observed, and the compliance rate in the first half of the study period was similar to that in the last half of the study period.

In summary, this study found that the majority of acute atypical antipsychotic ingestions reported to Texas poison centers during a recent 8-year period were managed according to a simplified version of recommended triage algorithm. However, over one-third were not managed according to these guidelines. Compliance varied by reported or estimated dose, being lowest for doses greater than the threshold dose but less than or equal to twice the threshold dose. This suggests that the guidelines may need to be adjusted in the future.

\section{References}

1. Litovitz TL, Klein-Schwartz W, Rodgers GC, Cobaugh DJ, Youniss J, Omslaer JC, May ME, Woolf AD, Benson BE (2002) 2001 annual report of the American Association of Poison Control Centers Toxic Exposure Surveillance System. Am J Emerg Med 20:391-452

2. Watson WA, Litovitz TL, Rodgers GC, Klein-Schwartz W, Youniss J, Rose SR, Borys D, May ME (2003) 2002 annual report of the American Association of Poison Control Centers Toxic Exposure Surveillance System. Am J Emerg Med 21:353-421

3. Watson WA, Litovitz TL, Klein-Schwartz W, Rodgers GC, Youniss J, Reid N, Rouse WG, Rembert RS, Borys D (2004) 2003 annual report of the American Association of Poison Control Centers Toxic Exposure Surveillance System. Am J Emerg Med 22:335-404

4. Watson WA, Litovitz TL, Rodgers GC, Klein-Schwartz W, Reid N, Youniss J, Flanagan A, Wruk KM (2005) 2004 Annual report of the American Association of Poison Control Centers Toxic Exposure Surveillance System. Am J Emerg Med 23:589-666

5. Lai MW, Klein-Schwartz W, Rodgers GC, Abrams JY, Haber DA, Bronstein AC, Wruk KM (2006) 2005 Annual Report of the American Association of Poison Control Centers' national poisoning and exposure database. Clin Toxicol (Phila) 44:803-932

6. Bronstein AC, Spyker DA, Cantilena LR, Green J, Rumack BH, Heard SE (2007) 2006 annual report of the American Association of Poison Control Centers' National Poison Data System (NPDS). Clin Toxicol (Phila) 45:815-917

7. Bronstein AC, Spyker DA, Cantilena LR, Green JL, Rumack BH, Heard SE (2008) 2007 Annual Report of the American Association of Poison Control Centers' National Poison Data System (NPDS): 25th Annual Report. Clin Toxicol (Phila) 46:927-1057

8. Cobaugh DJ, Erdman AR, Booze LL, Scharman EJ, Christianson G, Manoguerra AS, Caravati EM, Chyka PA, Woolf AD, Nelson LS, Troutman WG (2007) Atypical antipsychotic medication poisoning: an evidence-based consensus guideline for out-ofhospital management. Clin Toxicol (Phila) 45:918-942

9. Forrester MB, Parra G (2008) Compliance with selective serotonin reuptake inhibitor triage guidelines by Texas poison control centers. J Toxicol Environ Health A 71:304-309

10. Nelson LS, Erdman AR, Booze LL, Cobaugh DJ, Chyka PA, Woolf AD, Scharman EJ, Wax PM, Manoguerra AS, Christianson G, Caravati EM, Troutman WG (2007) Selective serotonin reuptake inhibitor poisoning: an evidence-based consensus guideline for out-of-hospital management. Clin Toxicol (Phila) 45:315332 